\title{
Regenerative Anti Lock Braking System
}

\author{
Mohamed Nabil \\ Teaching Assistance, \\ Department of Mechatronics \\ Faculty of Engineering Ain Shams \\ University, Cairo, Egypt
}

\author{
Adham Mohamed \\ Doctor, \\ Department of Automotive \\ Faculty of Engineering Ain Shams \\ University, Cairo, Egypt.
}

\author{
Farid Tolba \\ Professor, \\ Department of Mechatronics \\ Faculty of Engineering Ain Shams \\ University, Cairo, Egypt
}

\begin{abstract}
The braking system of vehicles uses the usual technology of hydraulic braking that generates thermal energy out of the loss of kinetic energy resulting from difference in motion of pads and wheels. The Regenerative Braking System (RBS) works on converting the excess kinetic energy into electrical energy that can be used in recharging the car battery during the vehicle deceleration. The RBS has some limitations that are related to the vehicle speed; as in low speed the system is inefficient to convert the kinetic energy and generate current. Also the RBS is uncapable of completely stopping the vehicle regardless of the traveling speed. The study in this paper emphasizes the Regenerative Anti lock Braking System (RABS) in saving energy and reducing energy loss, also enhancing braking performance at low speed rates. RABS comprehensive model has been constructed on Matlab / Simulink for simulation purposes in order to collect reliable results about system perfomance and experimental test rig has been constructed on a hybrid golf cart in two different modes; one of which is speed reducing mode and the other one is stopping mode and shows multiple conditions of braking such as braking on non-slippery surfaces as dry-surface (asphalt) and braking on slippery surfaces as wet-surface (asphalt) and oily-surface (asphalt).
\end{abstract}

Keywords: Anti-lock Braking System, Regenerative Braking System, Hybrid Electric Vehicle, Motor Generator, State Of Charge.

\section{INTRODUCTION}

Nowadays, saving energy becomes important because of decreasing amount of petroleum and problems of energy. The total energy dissipated through braking during an urban drive cycle may reach up to $34 \%$ of the total traction energy [1]. The results show that, the braking energy which dissipates as thermal energy can represent more than $70 \%$ of the required useful motor-energy during an urban drive cycle [2]. According to the energy law of conservation, the energy cannot be destroyed nor created, but changes from one type into another one, therefore, the RBS is used in most hybrid vehicles with assistance of conventional hydraulic brakes to get the complete stopping of vehicles and reducing energy loss that can be reused again [3]. The RBS makes the hybrid electric vehicles capable of recovering a significant amount of electric energy [4-5]. Studies show that vehicles consume about one half to one-third of the energy required for the operation of the vehicle in braking by using a conventional hydraulic brake. The RBS is used to reduce energy loss and transform lost energy into another form of reusable energy. The energy saved by RBS ranges from $8 \%$ to $25 \%$ of the lost energy according to driving conditions, and it's more efficient for frequently applied braking [3]. In the regenerative braking in Hybrid Electric Vehicles (HEVs) area, some studies have focused on developing regenerative models [6], simulation of regenerative system models [7] and motor control [8]. The Regenerative cooperation brake system which HEV are generally equipped with has stroke simulation. This paper focuses on regenerating the losses of energy in braking at lower speeds by using a high speed ratio reaching to $1: 75$ in order to make sure that the generator speeds in the range of generating current at lower speeds of vehicles in different surface conditions. The generator load torque with a high gear ratio is used to apply braking torque and the anti lock braking is performed by controlling the field current of the generator according to the slip- ratio desired between wheel's speed and vehicle speed.

\section{SYSTEM MODELING}

\section{A. Modeling of Regenerative Anti lock Braking System}

Fig. 1, shows the schematic diagram of the RABS for a hybrid golf cart being studied in this paper. As shown in fig. 1, the Motor Generator (MG) shaft is connected to the rear wheel by a magnetic clutch, the magnetic clutch transmits the torque of the vehicle to the MG through two sets of sprockets chains each set of this sprockets chains has a sproket ratio reaching to 1:2.5 and a differential gearbox which has a large gear ratio reaching to $1: 12$, therefore, the speed ratio between the wheel and the MG shaft reaches to 1:75.

RABS dynamic model consists of five main blocks shown in fig. 2:

- vehicle and wheel dynamics

- MG dynamics

- Mechanical brake system

- Controller

- Observer. 


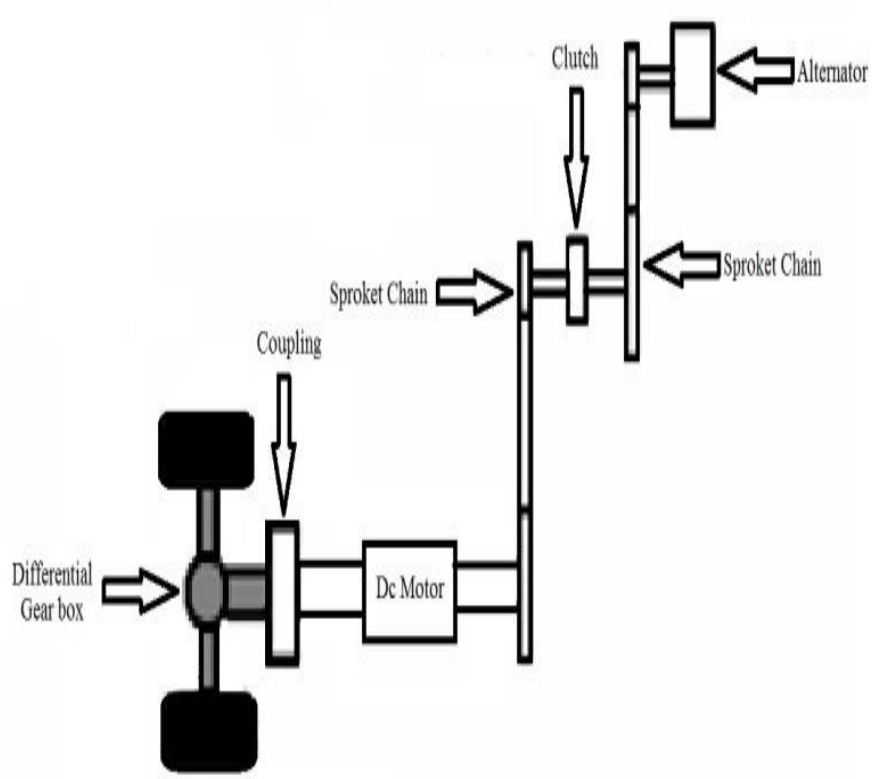

Fig. 1. Schematic diagram of Regenerative Anti lock Braking System

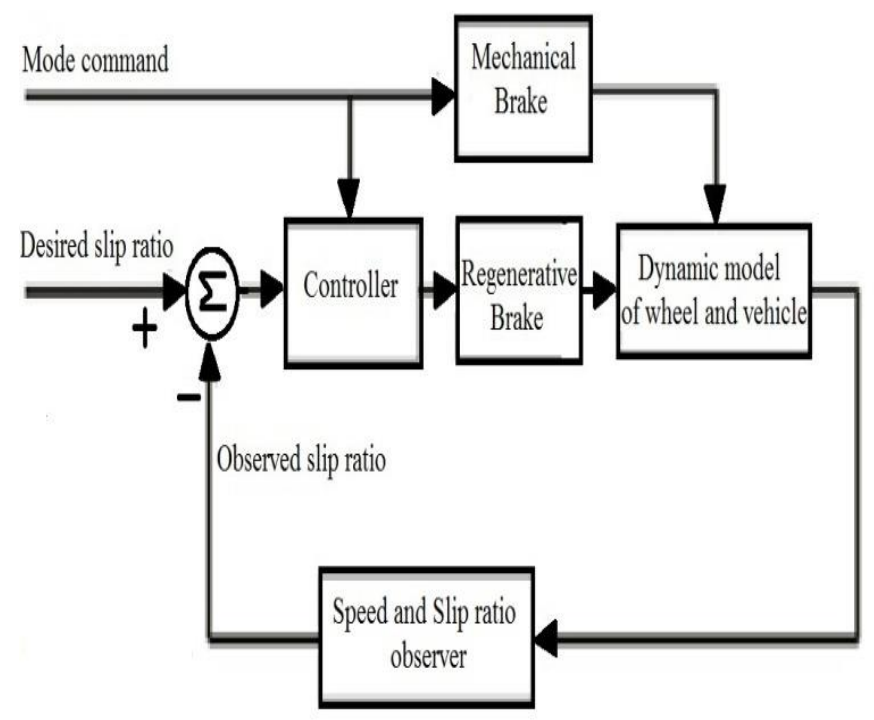

Fig. 2. Regenerative system dynamic model (Adapted from. [1])

\section{B. Vehicle and Wheel dynamics}

Vehicle and wheel dynamic block accounts for vehicle dynamics, wheel dynamic and road conditions. A model of two wheels for HEV, which this paper studies its braking is shown in fig. 3. It is possible to take the wind effect force, the force of hill climbing and rolling resistance into consideration but these forces are simple and cannot be taken into consideration because of the wind speed is random and may be with the direction of vehicle braking or in the direction of against to the vehicle braking, so the wind effect force cannot be taking into consideration, also the vehicle may be in the direction of climbing the hill or in the direction of down warding the hill, so the hill climbing force is random and cannot be taking into consideration, but for the rolling resistance, the rolling resistance force acts in the direction of retarding in vehicle speed and will reduce the stopping distance, this rolling resistance force is small with reference to the braking force so the rolling resistance force can be neglected. The tire deformation increases when the wheel be rotating at high speeds by the centrifugal force effect and decreases by the weight transforming at braking, therefore, the tire deformation is not taking into account because of this paper emphasizes the performance of the RABS at low speed. In this figure, $F_{r}$ is the force of braking acting on the rear wheel, $\mathrm{N}_{\mathrm{r}}$ is a normal force on the wheel, $\mathrm{T}_{\mathrm{r}}$ is tire torque and $\mathrm{R}$ is the wheel radius. The ratio of slip of the vehicle wheel is the relative difference between the linear wheel speed and the vehicle speed and can be expressed as:

$$
S=\frac{V-R \omega}{V}
$$

Where $\mathrm{V}$ is the speed of the vehicle, $\omega$ is the wheel angular speed and $\mathrm{R}$ is the wheel radius. The braking force that is shown in fig. 3 is expressed as:

$$
F_{\mathrm{r}}=\mu_{\mathrm{r}}\left(\mathrm{s}_{\mathrm{r}}\right) \mathrm{N}_{\mathrm{r}}
$$

Where $S_{r}$ is the slip ratio of rear wheel $\mu_{\mathrm{r}}$ is the coefficient of adhesion between the tire of rear wheel and the road surface which is a function of the ratio of slip (s) Also, $\mathrm{N}_{r}$ is the rear wheel tire normal force by neglect the force of hill climbing, wind force and rolling resistance, the motion equation of the vehicle can be expressed as:

$$
M \frac{d v}{d t}=-F_{\mathrm{r}}
$$

The wheel motion equation can be expressed as:

$$
J_{\mathrm{r}} \frac{d \omega}{d t}=-T_{\mathrm{r}}+\left(\mathrm{R} \times \mathrm{F}_{\mathrm{r}}\right)
$$

Where $J_{r}$ is the moment of inertia of the wheel and $T_{r}$ is the total torque of braking.

The force of braking is a function of the coefficient of adhesion between a terrain and tire and is determined by the condition of the road surface and the slip-ratio as shown in expression (2). Fig. 4, shows the variations of road coefficient of adhesion versus the slip- ratio of the wheel. The coefficient of adhesion reaches its max value $\left(\mu_{\mathrm{m}}\right)$ at the critical ratio of slip $\left(S_{m}\right)$ for most conditions of the road. When the ratio of slip is below $\left(S_{m}\right)$, the traction force can be enhanced by increasing the ratio of slip. Once the ratio of slip exceeds $\left(S_{m}\right)$, the braking force will decrease because of the decreasing of the coefficient of adhesion down the value of sliding $\mu_{\mathrm{s}}$.

The adhesive coefficient in the lateral direction, a major factor in the stability and the steerability of the vehicle, increases by decreasing the slip-ratio. Therefore, to guarantee the stability and the steer ability of the vehicle, the slip-ratio has to be under the critical slip-ratio of $\left(S_{\mathrm{m}}\right)[10]$. 


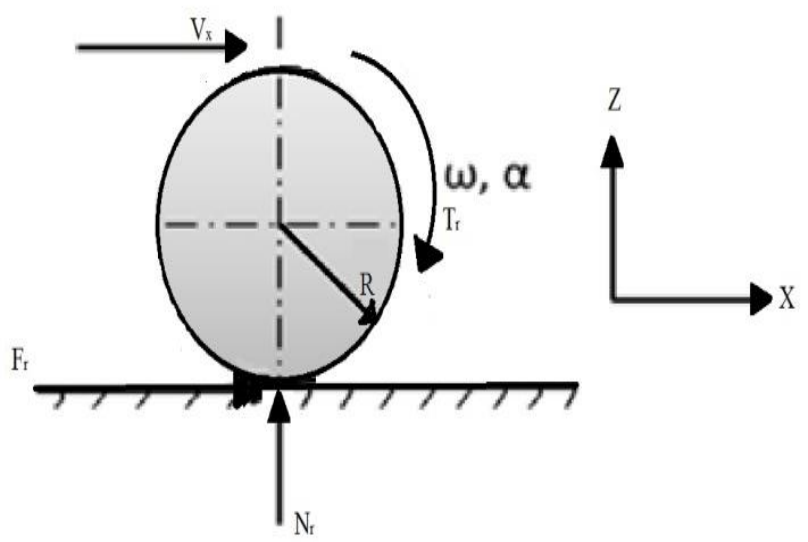

Fig. 3. Wheel model of Golf cart (Adapted from. [9])

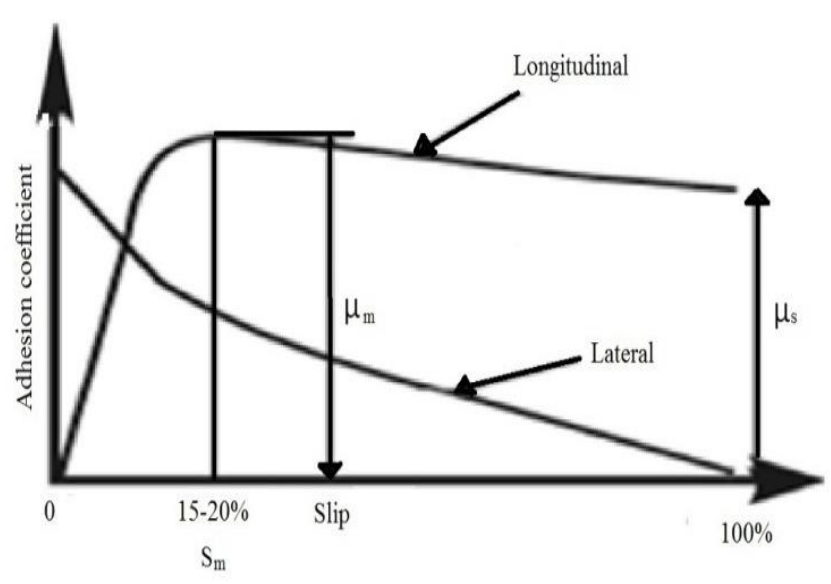

Fig. 4. Road adhesive coefficient (Adapted from. [1])

\section{Dynamics of Motor Generator}

The MG dynamic block includes the MG, batteries and generator electric field switch transistor. $\mathrm{MG}$ and the rear wheels are coupled together to drive a train. Fig. 5, shows a schematic diagram of RABS.

As shown in fig. 5, the two infrared proximity sensors give signals of rear and front wheel pulses to the controller 1, then the controller 1 calculates the angular speed of the rear wheel, then the controller 1 calculates the slip-ratio of the on road vehicle and compares the favorable slip-ratio with calculated on road vehicle slip-ratio, and according to this comparison, the controller 1 switches the transistor to be $\mathrm{ON}$ or OFF and therefore switches the magnetic field of the alternator. The controller 2 takes the signal from the current sensor, and then calculates the alternator braking torque.

In the electric vehicle under study, the efficiency of the MG is the ratio of electric output power to mechanical input power.

$$
\eta=\frac{\mathrm{P}_{\text {out }}}{\mathrm{p}_{\text {in }}}
$$

Where $\mathrm{P}_{\text {out }}$ is electrical output power, $\mathrm{P}_{\text {in }}$ is mechanical input power and $\eta$ is the MG efficiency.

By the law of conservation of energy, the mechanical input power is equal to the electrical output power plus the losses:

$$
\mathrm{P}_{\text {in }}=P_{\text {out }}+\mathrm{P}_{\text {loss }}
$$

So that:

$$
\eta=\frac{\text { Pout }}{\left(\text { Pout }_{\text {o }}+\text { Ploss }\right)}
$$

The map of an efficiency of the MG is shown in fig. 6.

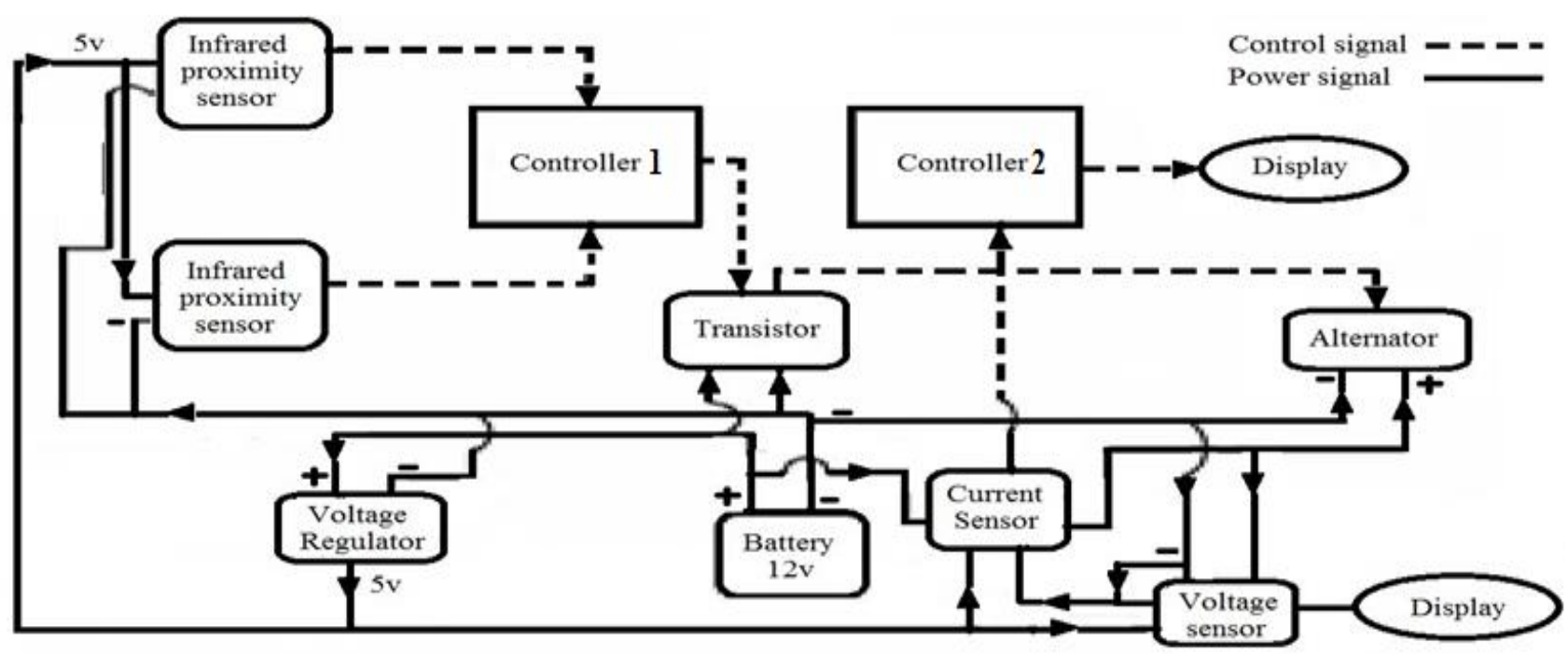

Fig. 5. Schematic diagram of regenerative anti lock braking system 


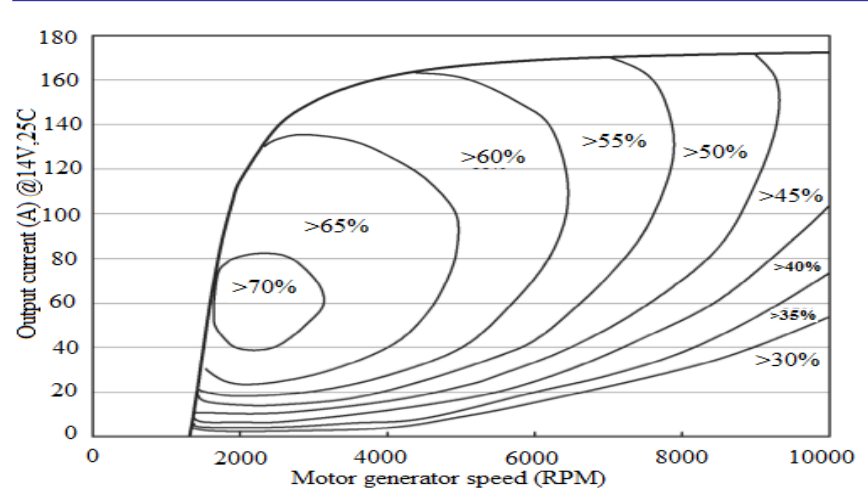

Fig. 6. Characteristics of efficiency of an Motor Generator (Adapted from.

During braking, the RABS works to prevent the locking of the wheel because of the locking of wheels doesn't only lead to the increase of stopping distance, but also it lowers the amount of recovered energy. That is because in locking wheels case, the rotating speed is close to zero which decreases the maximum amount of power for MG. Regenerated energy by the MG is charged to the battery. The battery stores a part of this electrical energy, according to its available capacity and other physical limitations. Rarely the regenerative braking cannot occur is only when the battery is already fully charged [12]. There are three 12 Volt deep cycle batteries utilized in the golf cart under study each with $100 \mathrm{Ah}$ rated capacity. The battery charge level is expressed by the State Of Charge percentage (SOC). The amount of energy absorbed in a battery is determined through the MG dynamic block.

\section{Regenerative Anti lock Braking System mechanical brake}

The mechanical brake in the RABS is a normal mechanical brake which acts on rear wheels only, this mechanical brake has a constant braking torque, which equal to the maximum torque generated by the MG and uses in the second mode of braking (stopping mode). The total torque of braking of the rear wheel is a sum of mechanical braking and generator braking torque which is provided by MG.

\section{BRAKING CONTROLLER}

The amount of code used in control systems of the regenerative braking varies in different estimates for different vehicles [13], it is estimated that modern hybrid electric vehicles run approximately 100 million lines of code [14]. The inputs of the controller unit of the RABS are the angular speed of the rear wheel and the command of the selected mode, (speed reducing or stopping modes). In the brake controller module, the brake control strategy determines the braking torque according to the type of braking mode. There are two modes; one of which is the speed reducing mode, the braking torque in the speed reducing mode is applied by MG torque only. The other one is stopping mode, the braking torque in stopping mode is a sum of constant mechanical brake and MG braking torque without using any conventional mechanical anti-lock braking system [14]. If locking of the wheels is predicted by the controller. The controller opens the transistor of electric field generator to switch off the MG torque to allow the wheel to reach their optimum ratio of slip. If the ratio of slip of the rear wheel is below the desired slip-ratio, the braking torque of MG is applied to the wheels with constant mechanical brake. If the ratio of slip of the rear wheels exceeds the desired slip-ratio the brake controller lets the constant mechanical brake and stops the MG torque to allow the wheels accelerate. When the risk of locking has removed, The MG torque is applied again to the wheel. The decision algorithm of brake controller is shown in fig. 7.

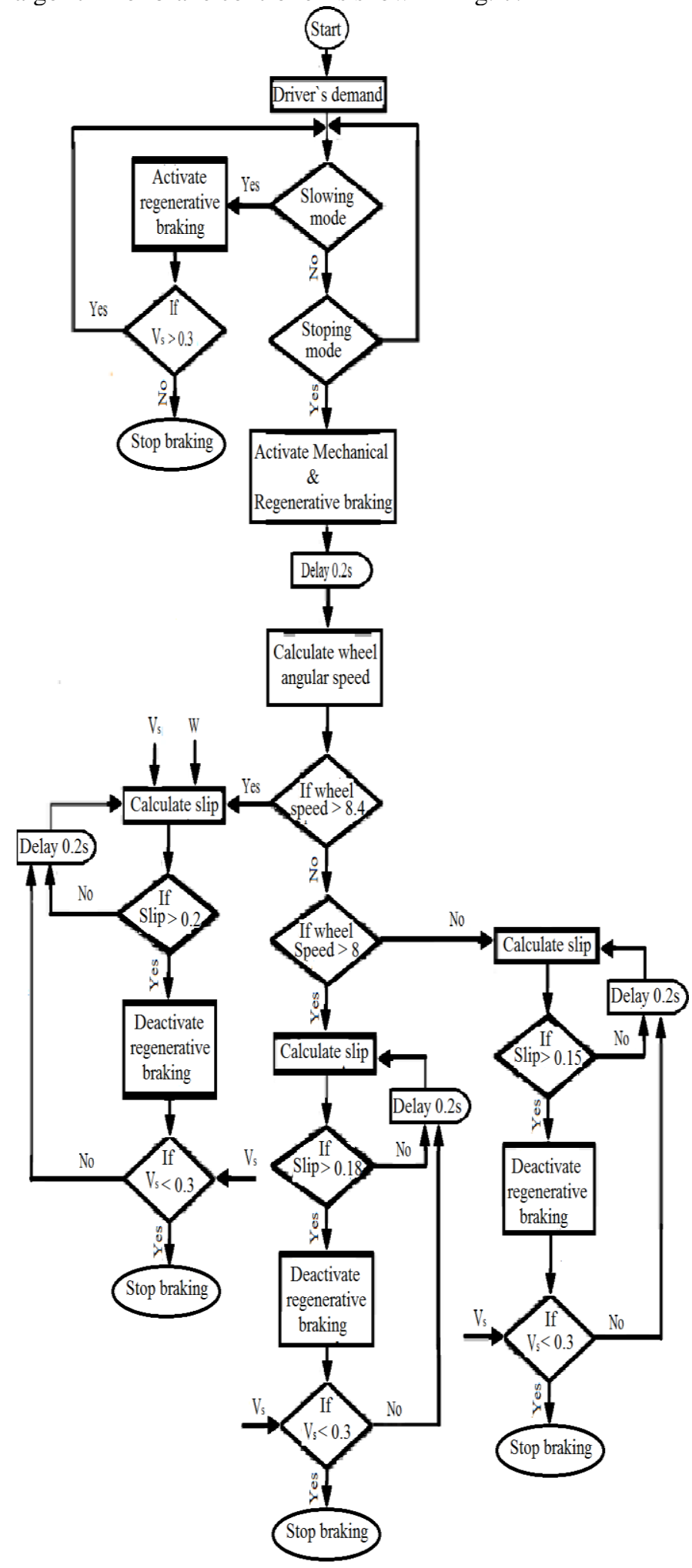

Fig. 7. Flow chart for the Brake control 
As shown in fig. 7 the decision of brake controller depends on the detection of the road surface condition. The curves of the coefficient of adhesion with slip-ratio in various road conditions are illustrated in fig. 8 .

\section{SPEED AND SLIP-RATIO OBSERVER}

The function of the Speed and Slip-ratio observer block is to calculate the vehicle absolute velocity and the slip-ratio of the wheel from the values of wheel applied torque and wheel acceleration. To compute the absolute velocity of the vehicle, vehicle deceleration is calculated by the derived formula of vehicle dynamic then integrated.

Where $\mathrm{R}$ is the wheel radius, $\mathrm{F}_{\mathrm{r}}$ is the force of braking acting on the rear wheel, $T_{r}$ is tire torque, $\omega$ is the wheel angular speed and $\mathrm{J}_{\mathrm{r}}$ is the moment of inertia of the rear wheel.

From expression (4) where no locking of rear wheels $(\omega>0)$, the total torque of braking acting on a vehicle is:

$$
R \times F_{\mathrm{r}}=J_{\mathrm{r}} \frac{d \omega}{d t}+\mathrm{T}_{\mathrm{r}}
$$

Where

$$
F_{\mathrm{r}}=\mathrm{M} \frac{d v}{d t}
$$

Therefore, the vehicle deceleration becomes:

$$
\frac{d v}{d t}=\frac{J_{\mathrm{r}} \frac{d \omega}{d t}+\mathrm{T}_{\mathrm{r}}}{M R}
$$

$\mathrm{V}_{0}$ and $\mathrm{V}_{\mathrm{r}}$ are the vehicles initial absolute speed initial rear wheels linear speed respectively. By integrating the absolute velocity of the vehicle can be obtained as:

$$
V=V_{0}-\frac{J_{\mathrm{r}}}{M R^{2}}\left(V_{\mathrm{r}}-V_{0}\right)-\frac{\int T_{\mathrm{r}} d t}{M R}
$$

Where $T_{r}$ is the torque of braking of rear wheels. Then the slip-ratio of the rear wheel can be calculated by the expression (1).

In the golf car that is under study in this paper, there are two wheel encoders with the proximity switch systems, one of them is attached to the rear wheel and the other one to the front wheel of the golf cart, according to the number of pulses that generates by the encoder the angular speed of the wheel is calculated, and because of no braking is applied to the front wheel, the golf cart absolute velocity is calculated from the angular speed of the front wheel by the expression:

$$
V=\omega_{\mathrm{f}} * \mathrm{R}
$$

Where $\omega_{\mathrm{f}}$ is the angular speed of the front wheel.

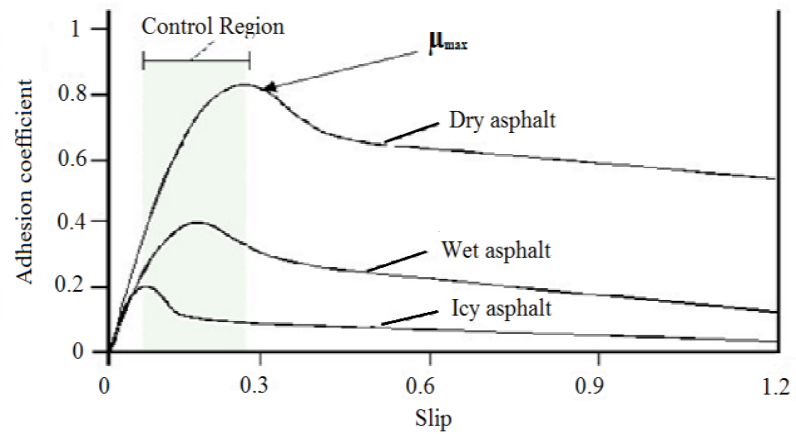

Fig. 8. Coefficient of adhesion with slip ratio in various road conditions (Adapted from. [9])

\section{DESIGN OF EXPERIMENTAL SETUP}

To transfer from the environment of simulation work done on the computer into the actual system an experimental test rig has been constructed on a golf cart. The golf cart in the experimental test rig has specifications of a maximum speed of $25 \mathrm{~km} / \mathrm{h}$, mass of $750 \mathrm{~kg}$ and wheels radius of $0.3 \mathrm{~m}$. The longitudinal force of the tire applied on the surface of the road has been constructed as the load torque to the MG. There are two modes of operation; the first one is executed through the activation of the clutch of regenerative braking system only, which transmits the torque and motion from the rear wheel to the MG through a differential gear box and a set of sprockets and chains. The other one is executed through the activation of both braking torques (mechanical torque and regenerative anti lock braking torque). The switching mechanism for the anti lock braking system is carried out by controlling the field current of MG by transistor according to the speed rates of the vehicle and the wheels. The electrical power is calculated and measured by the controller, the current sensor and voltage sensor. The experimental test rig setup is shown in fig. 9.

The photo interrupter of the infrared sensor attached to the rear wheel of the vehicle is shown in fig. 10, which gives signal for the angular speed for the rear wheel.

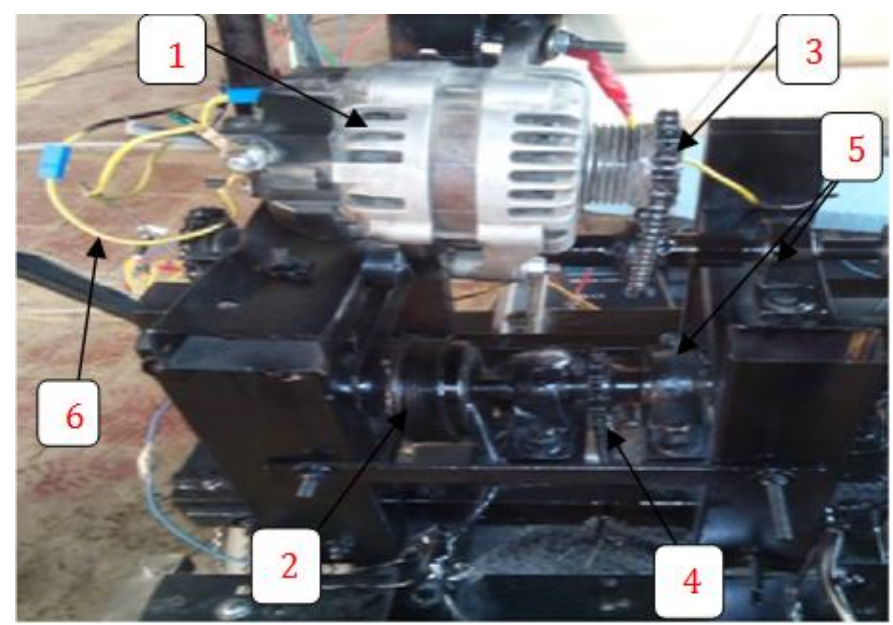

Fig. 9. Experimental test rig setup 1.Alternator 2.Mgnetic clutch 3. First sprocket chain 4.second sprocket chain 5. Beraings chairs 6.electric wires 


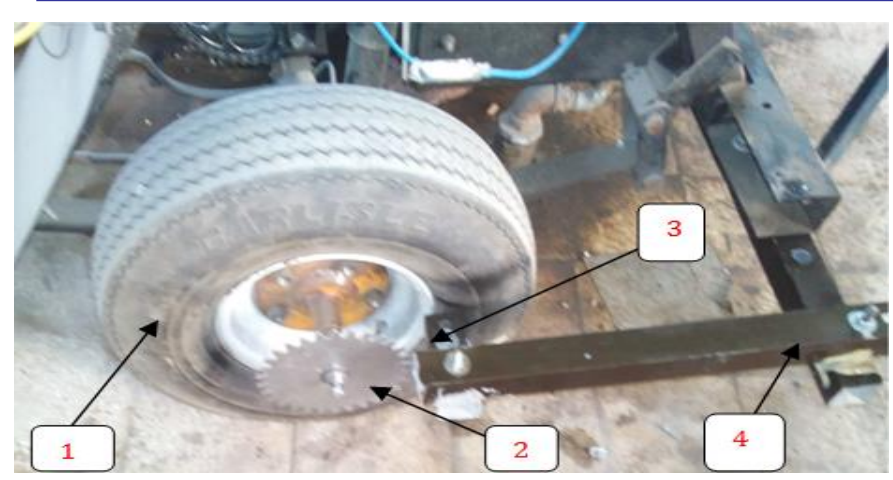

Fig. 10. The photo interrupter of an infrared sensor which used to measure wheel speed 1.Rear wheel 2.Encoder wheel 3. Infrared sensor 4. Sensor fixation mechanism

\section{RESULTS}

According to on-road vehicle testing, the braking system is tested under normal weather conditions (pressure and temperature) but on different types of terrain (dry, wet and oily surfaces) by allowing the vehicle to accelerate to the max speed during the test $9.5 \mathrm{~km} / \mathrm{h}$ then apply braking according to the type of brakes (reducing speed or stopping) in test and measure the brakes performance parameters. A simulation model is constructed and simulated in the same conditions of the on-road vehicle testing but there are some variations in test conditions between the on-road vehicle testing and the simulation model, these variations are ranged from $4 \%$ to $7 \%$, these variations result from some factors that hasn't been taken into consideration during the simulation as wind effect force, the force of hill climbing and rolling resistance as previously mentioned.

The Results are divided into two types the first type is from the simulation and the second type is from on road vehicle testing, They are compared together through the points of the rear wheel's slip-ratio, wheel speed, vehicle speed, stopping distance, stopping time, load torque and regenerated energy by using the RABS. In the simulation results shown on figures of this section, the vehicle`s speed is determined by the vehicle dynamic model, but in the test rig is measured by infrared encoder sensor.

The results have been gathered for two modes, speed reducing mode and stopping mode. In the stopping mode, the results are classified in two conditions, stopping on non-slippery roads and stopping on slippery roads. In the first test (speed reducing mode on dry-surface (asphalt)) the source of braking torque is generator load torque and the results of braking are shown in the table (1).

Fig. 11 and fig. 12 illustrate wheel speed and vehicle speed in speed reducing state.

TABLE I. Braking performance in speed reducing state on the dry-surface (asphalt)

\begin{tabular}{|c|c|c|}
\hline $\begin{array}{l}\text { speed reducing state on the dry- } \\
\text { surface (asphalt) }\end{array}$ & Simulation & Test rig \\
\hline Stopping distance & $10 \mathrm{~m}$ & $9.8 \mathrm{~m}$ \\
\hline Stopping time & $9.5 \mathrm{~s}$ & $9.3 \mathrm{~s}$ \\
\hline Mean slip ratio & 0.05 & 0.045 \\
\hline Regenerated energy & $663 \mathrm{~J}$ & $635 \mathrm{~J}$ \\
\hline
\end{tabular}

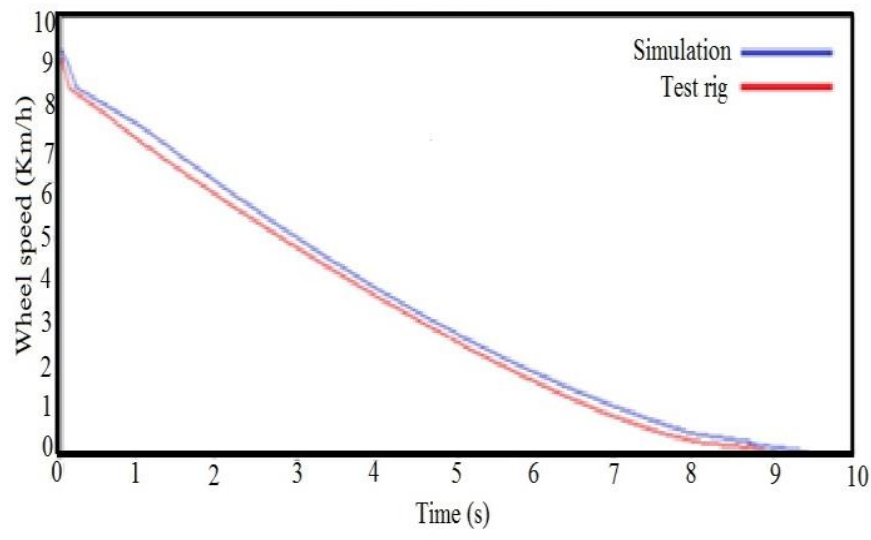

Fig. 11. Simulation and test rig Wheel speed in speed reducing state on the dry-surface (asphalt)

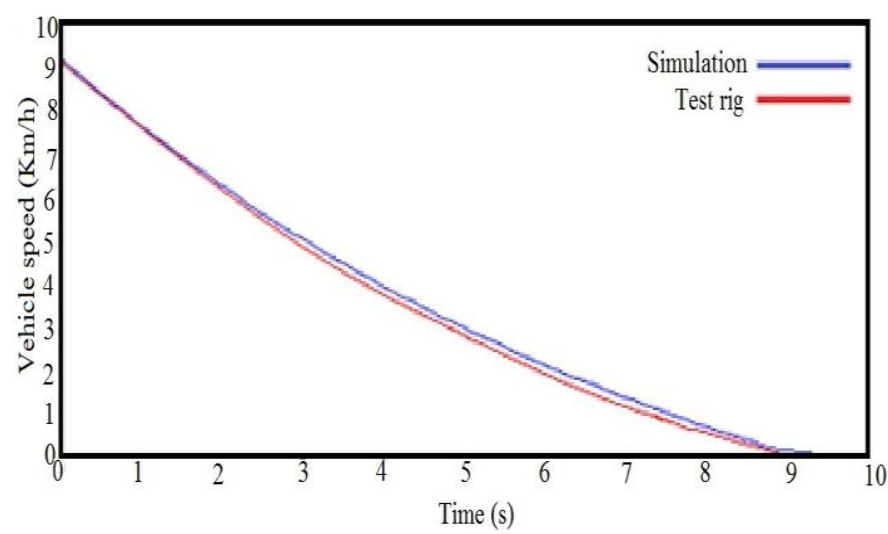

Fig. 12. Simulation and test rig Vehicle speed in speed reducing state on drysurface (asphalt)

As shown in these figures, there is not any locking in wheels and after 0.2 seconds from starting of braking the values of vehicle speed and wheel speed may be same, therefore, the most of the kinetic energy is converted into electric energy. In fig. 13, the wheel slip- ratio versus time chart is shown and the value of slip-ratio does not exist the value of 0.07

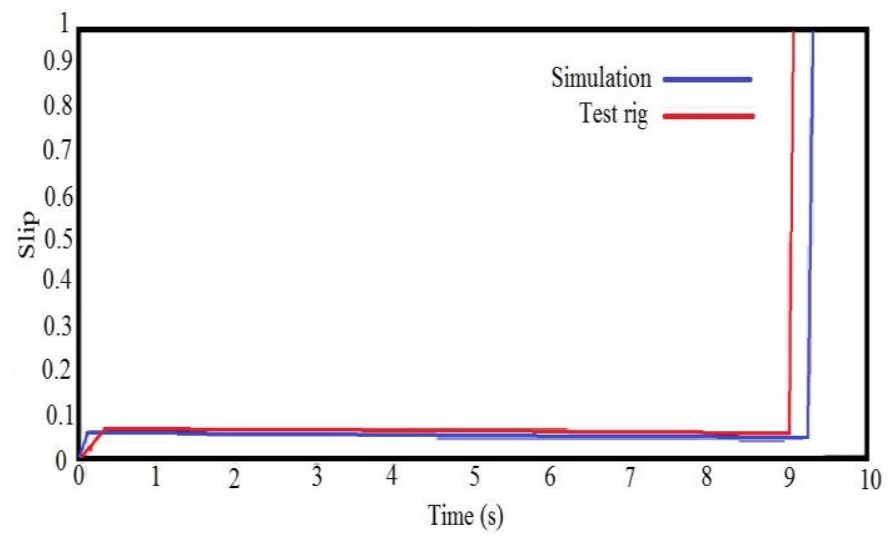

Fig. 13. Simulation and test rig Rear wheel slip-ratio in speed reducing state on the dry-surface (asphalt) 


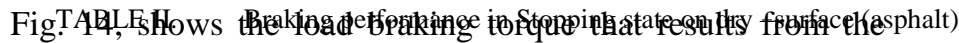
generator and gearbox according to the regenerated current and battery state of charge.

Fig. 15, shows the regenerated current curve, which likes the load torque curve due to the proportional relation between the load torque and current from the generator.

\begin{tabular}{|c|c|c|}
\hline $\begin{array}{c}\text { Stopping state on the dry-surface } \\
\text { (asphalt) }\end{array}$ & Simulation & Test rig \\
\hline Stopping distance & $7 \mathrm{~m}$ & $6.6 \mathrm{~m}$ \\
\hline Stopping time & $5.4 \mathrm{~s}$ & $5.2 \mathrm{~s}$ \\
\hline Mean slip ratio & 0.09 & 0.1 \\
\hline Regenerated energy & $405 \mathrm{~J}$ & $385 \mathrm{~J}$ \\
\hline
\end{tabular}

-surface (asphalt)

As shown in figure 17, the current being equal to zero after 8.5 seconds when the wheel speed tends to $0.314 \mathrm{~m} / \mathrm{s}$ because according to this wheel speed, the generator speed would be below 750 RPM (The speed that below it the generator cannot generate current).

In stopping test, there are two stopping conditions, the first one is non slippery stopping and the second one is slippery stopping as stopping on wet-surface (asphalt) and oily-surface (asphalt). In the stopping test, the sources of braking torque are the generator load torque and a constant mechanical torque -surface (eqphalt)! to the maximum value of generator load torque. The results of the test are presented in tables 2-3-4.

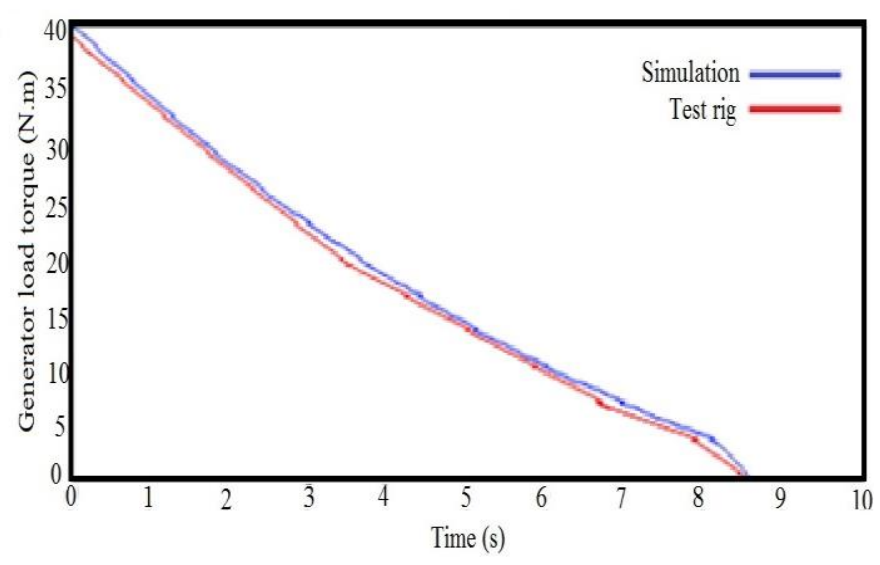

Fig. 14. Simulation and test rig Generator load torque in speed reducing state on the dry-surface (asphalt)

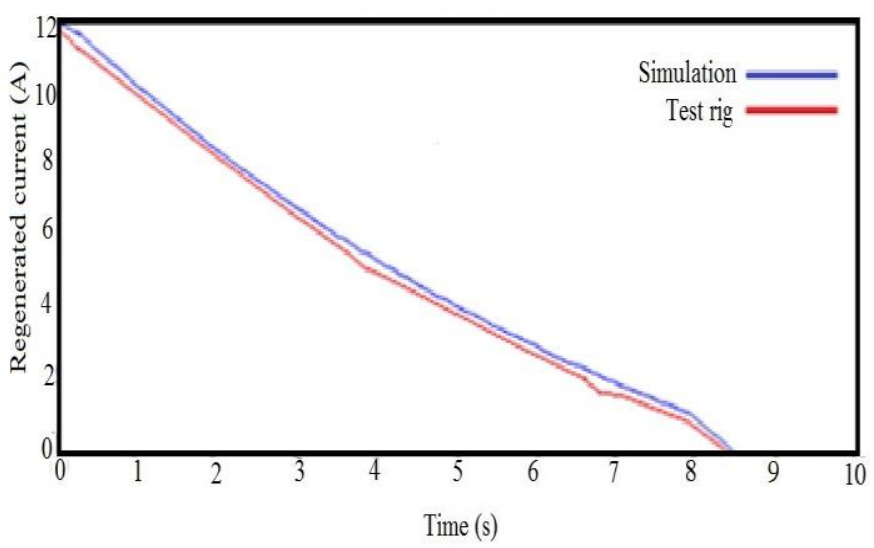

Fig. 15. Simulation and test rig Regenerated current in speed reducing state on the dry-surface (asphalt)

\begin{tabular}{|c|c|c|}
\hline $\begin{array}{c}\text { Stopping state on the wet- surface } \\
\text { (asphalt) }\end{array}$ & Simulation & Test rig \\
\hline Stopping distance & $8 \mathrm{~m}$ & $7.5 \mathrm{~m}$ \\
\hline Stopping time & $6 \mathrm{~s}$ & $5.9 \mathrm{~s}$ \\
\hline Mean slip ratio & 0.14 & 0.15 \\
\hline Regenerated energy & $395 \mathrm{~J}$ & $370 \mathrm{~J}$ \\
\hline
\end{tabular}

\begin{tabular}{|c|c|c|}
\hline $\begin{array}{c}\text { Stopping state on the oily- surface } \\
\text { (asphalt) }\end{array}$ & Simulation & Test rig \\
\hline Stopping distance & $10.2 \mathrm{~m}$ & $9.8 \mathrm{~m}$ \\
\hline Stopping time & $10.6 \mathrm{~s}$ & $10.59 \mathrm{~s}$ \\
\hline Mean slip ratio & 0.245 & 0.265 \\
\hline Regenerated energy & $378 \mathrm{~J}$ & $352 \mathrm{~J}$ \\
\hline
\end{tabular}

Fig. 16 and fig. 17, illustrate wheel speed and vehicle speed in stopping test on dry-surface (asphalt).

As shown in fig. 17, after 5 seconds from starting of braking there are changes in vehicle speed because the slip ratio of the wheel exceed the limit of 0.2 as shown in fig. 18 and the wheel tends to lock, therefore, the transistor switch is turned off the current of an electric field to the generator which lead to turning off the generator and decrease the generator load torque to no load torque and according to it the braking torque is a mechanical torque only.

Fig. 19 and fig. 20, show the load braking torque that results from the generator and meshed gearbox and current regenerated respectively.

As shown in the figures, the generator stopped generating current after 5.3 seconds from the braking start due to after 5.3 second the wheel speed will decreases than $0.314 \mathrm{~m} / \mathrm{s}$ and the generator speed will be below 750 RPM.

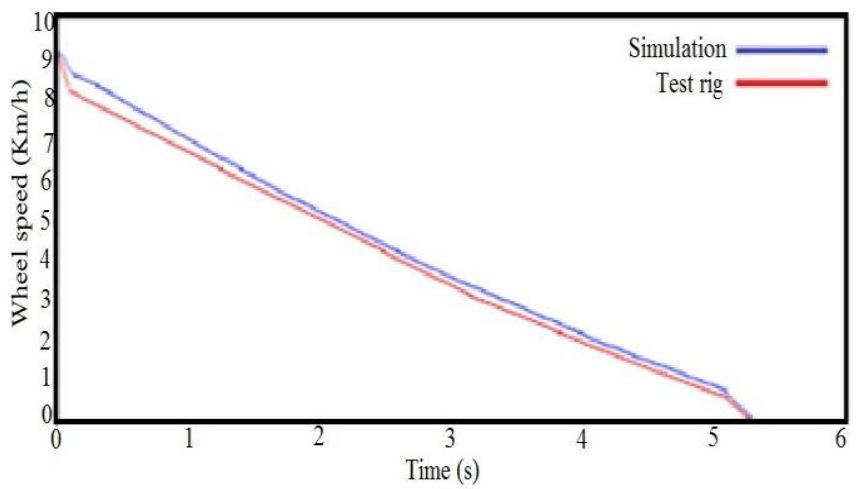

Fig. 16. Simulation and test rig Wheel speed in stopping station dry-surface (asphalt) 


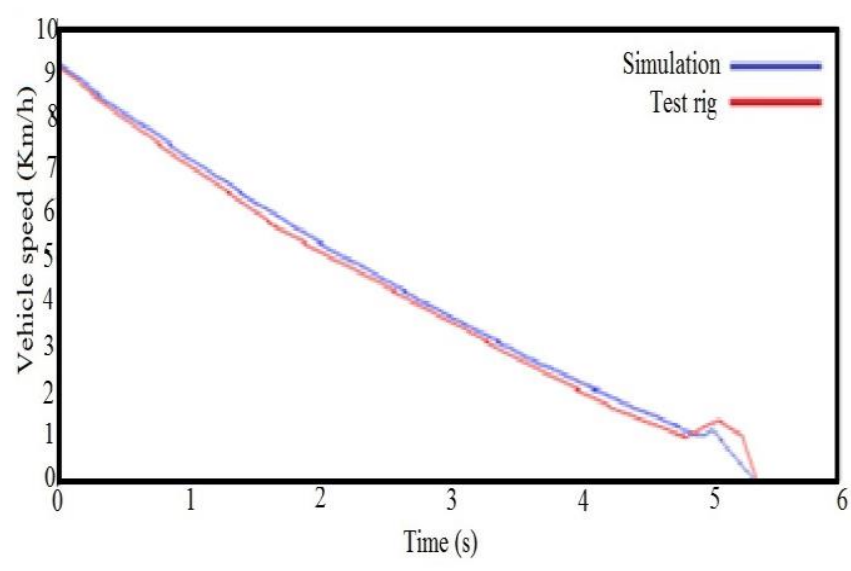

Fig. 17. Simulation and test rig Vehicle speed in stopping state on dry-surface (asphalt)

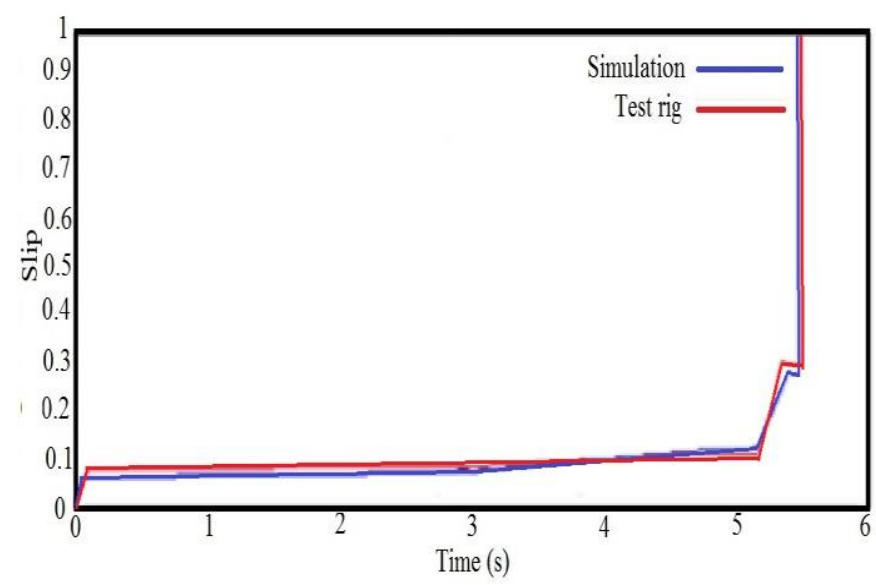

Fig. 18. Simulation and test rig Rear wheel slip ratio in stopping state on drysurafce (asphalt)

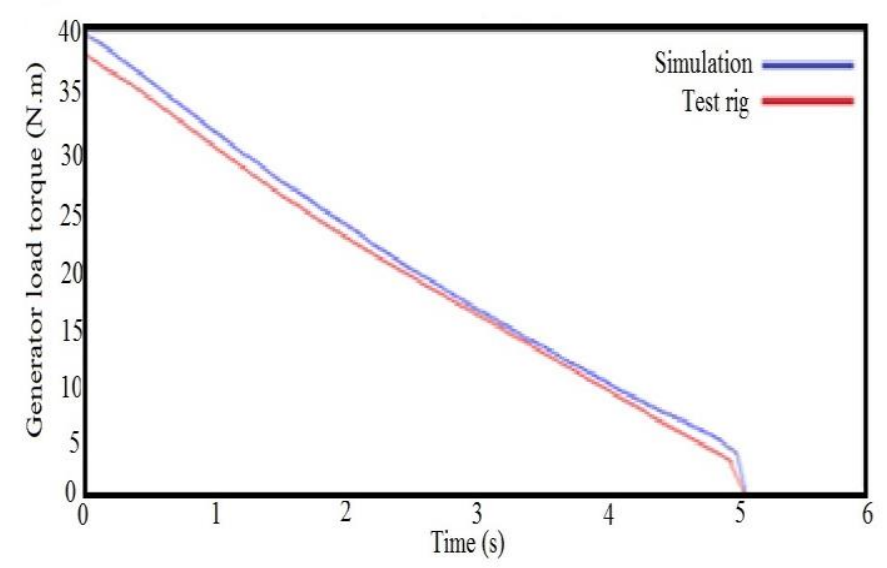

Fig. 19. Simulation and test rig Generator load torque in stopping state on drysurafce (asphalt)

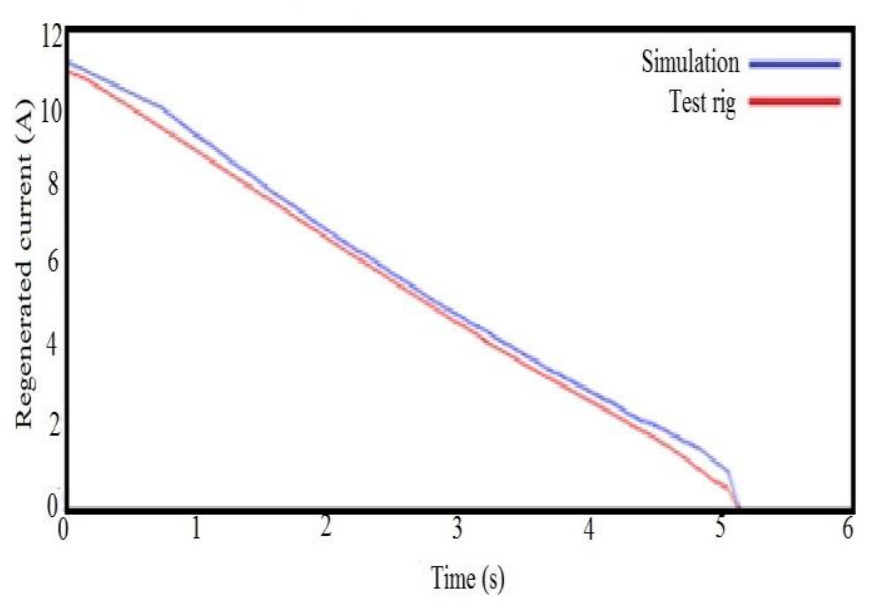

Fig. 20. Simulation and test rig Regenerated current in stopping state on drysurface (asphalt)

In slippery stopping conditions as stopping on wet-surface (asphalt) and oily-surface (asphalt), the wheel tends to lock during the braking more than the braking on the dry-surface (asphalt).

Therefore, the regenerated energy in this test is lower than the energy that regenerated in the dry-surface (asphalt) test, but the duration of the braking is significantly larger than on the dry-surface (asphalt) condition.

Therefore, a large amount of energy is dissipated through the mechanical brake.

Fig. 21, illustrate the wheel speed on wet asphalt and fig. 22, illustrate the vehicle speed on wet asphalt.

In the wet asphalt condition the wheel tends to lock at the end of the baking duration as shown in fig. 21 .

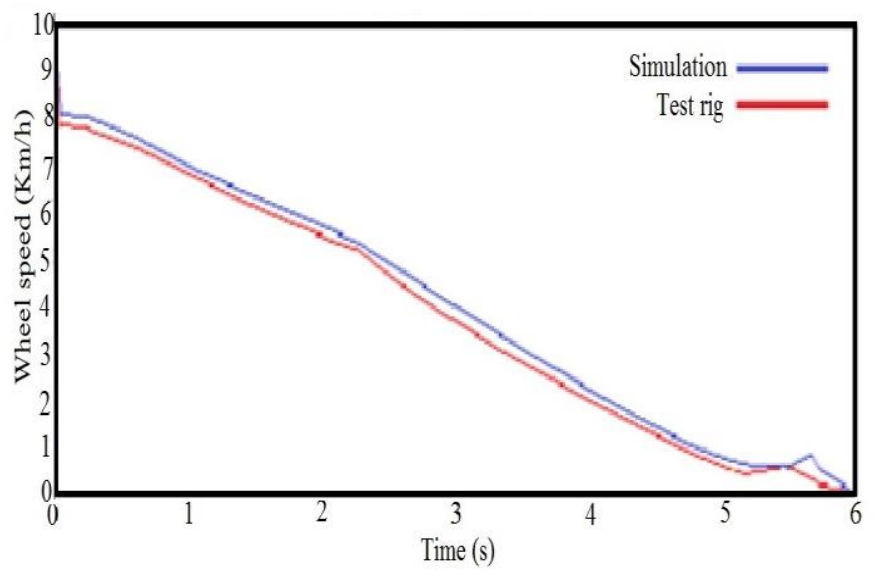

Fig. 21. Simulation and test rig Wheel speed in stopping state on wet-surface (asphalt) 


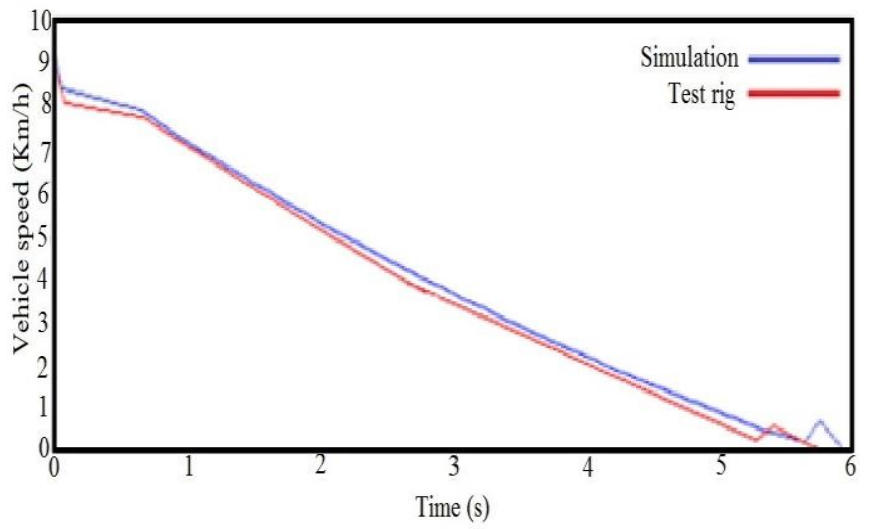

Fig. 22. Simulation and test rig Vehicle speed in stopping state on wet-surface (asphalt)

In fig. 23, the wheel slip ratio versus time chart is shown for wet asphalt.

Fig. 24 shows the generator braking torque, the fluctuation does not appear in the generator braking torque due to the wheel start tending to lock after the generator speed lower the 750 RPM.

In fig. 25, the current regenerated from the generator for wet asphalt conditions is shown.

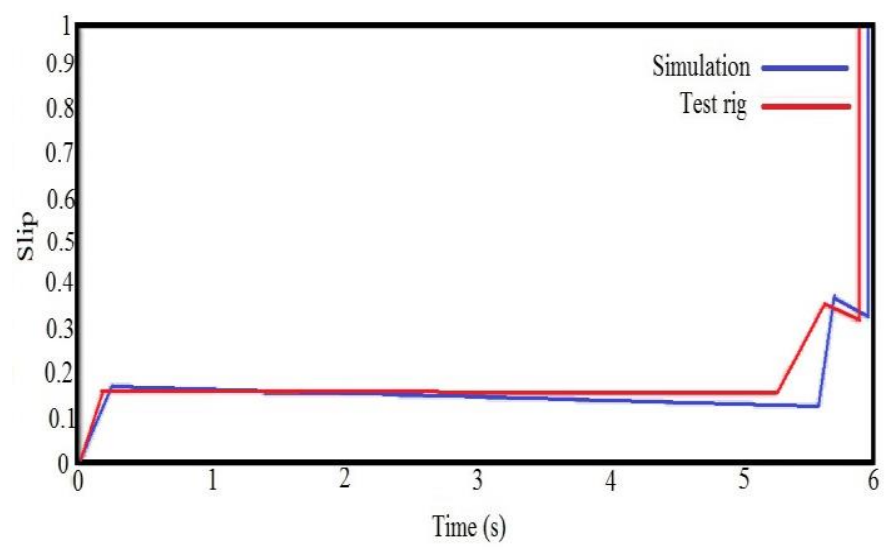

Fig. 23. Simulation and test rig Rear wheel slip ratio in stopping state on wet surface (asphalt)

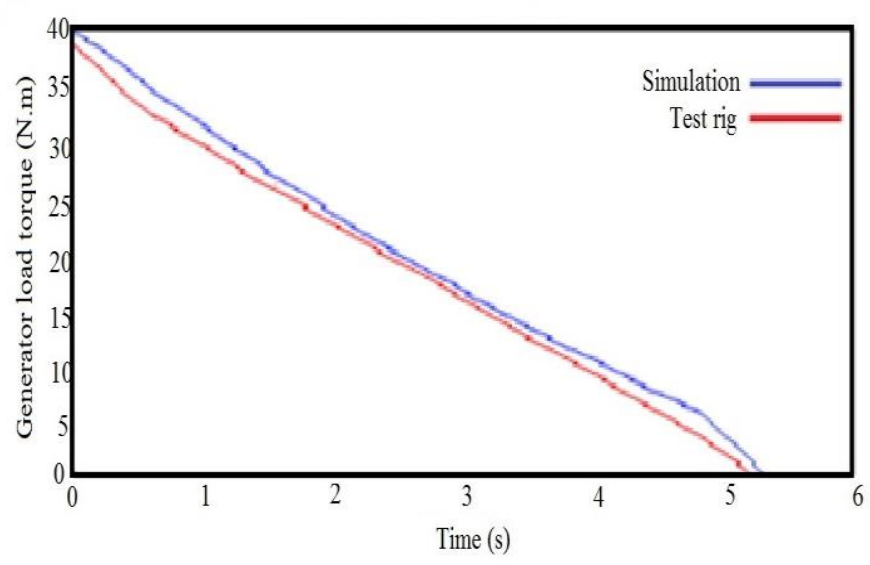

Fig. 24. Simulation and test rig Generator load torque in stopping state on wet-surface (asphalt)

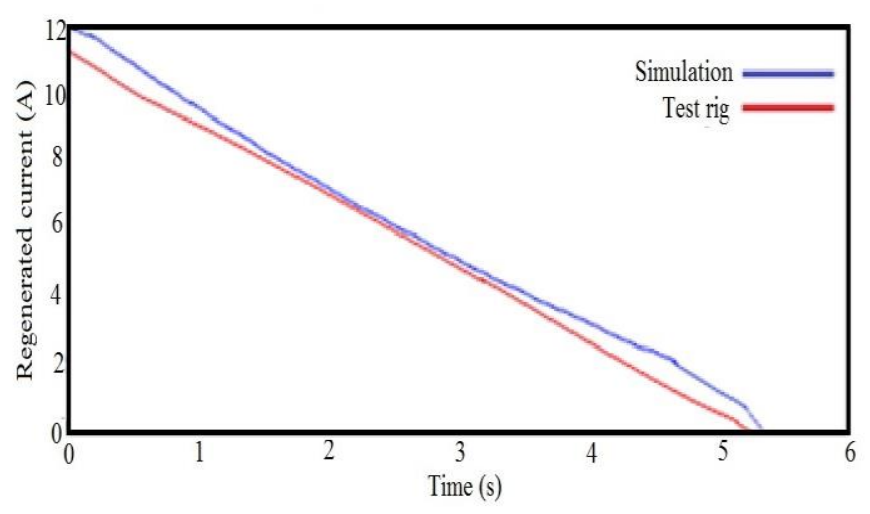

Fig. 25. Simulation and test rig Regenerated current in stopping state on wetSurface (asphalt)

The second test in slippery stopping conditions is on the oilysurface (asphalt). Fig. 26, Shows the wheel speed for stoping state on the oily-surface (asphalt), the fluctuation of the wheel appears at the start of braking.

Fig. 27, illustrate the vehicle speed on oily-surface (asphalt).

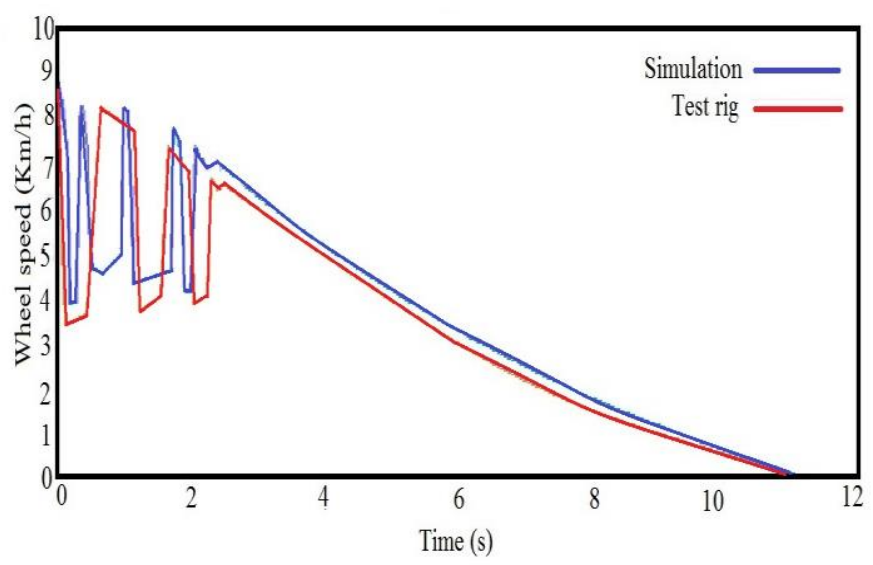

Fig. 26. Simulation and test rig Wheel speed in stopping state on the oilysurface (asphalt)

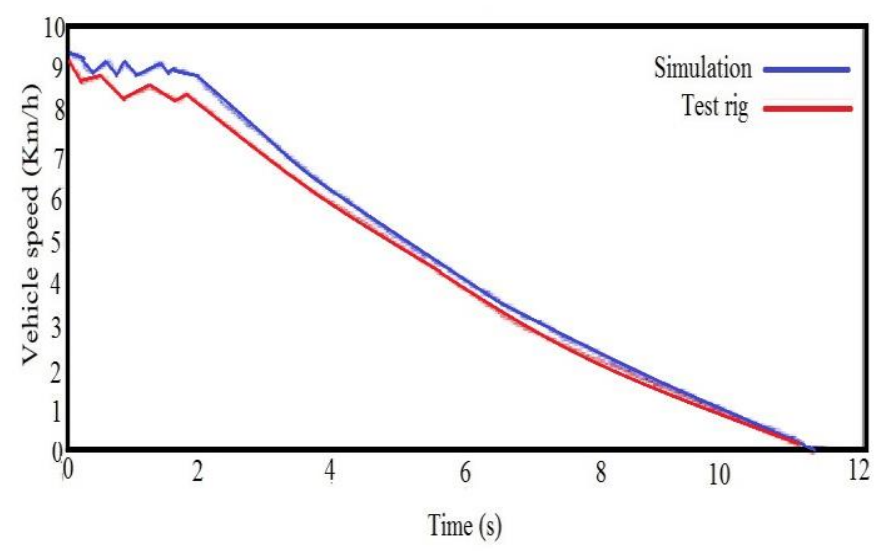

Fig. 27. Simulation and test rig Vehicle speed in stopping state on the oilysurface (asphalt) 
In fig. 28, The wheel slip-ratio versus time chart is shown for oilysurface (asphalt).

Fig. 29, Shows the generator braking torque for oily-surface (asphalt) condition, the fluctuation appears in the generator braking torque at the start of braking on the oily-surface (asphalt) condition due to the wheel tends to lock.

In fig. 30, The current regenerated from the generator for the oilysurface (asphalt) condition is shown.

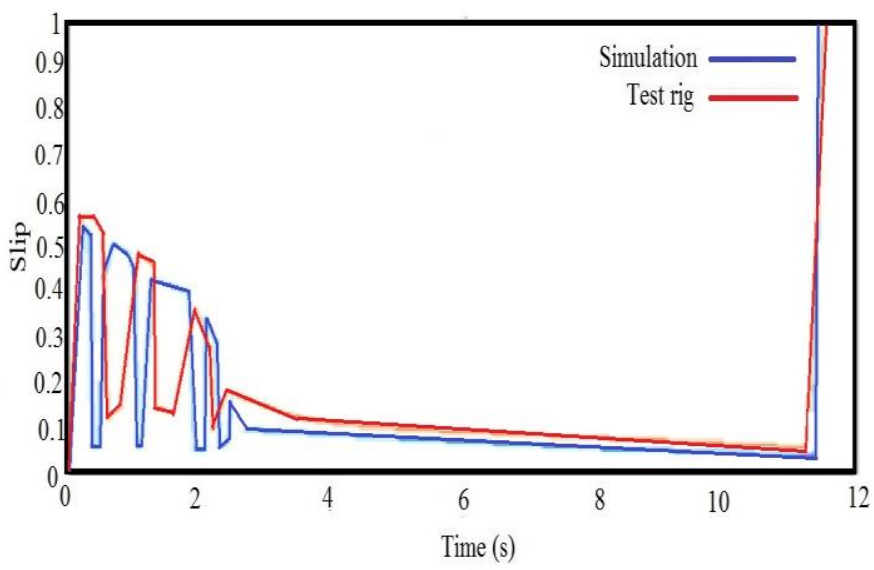

Fig. 28. Simulation and test rig Rear wheel slip-ratio in stopping state on the oily-surface (asphalt)

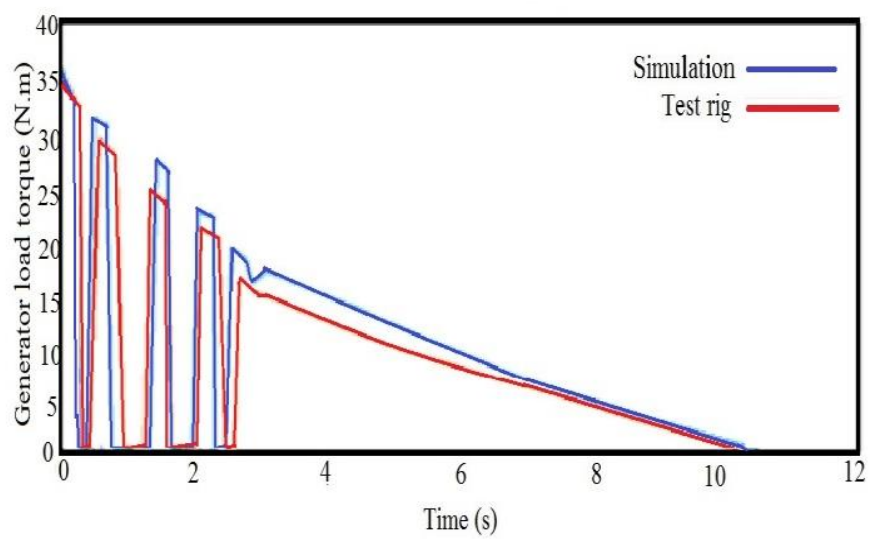

Fig. 29. Simulation and test rig Generator load torque in stopping state on the oily-surface (asphalt)

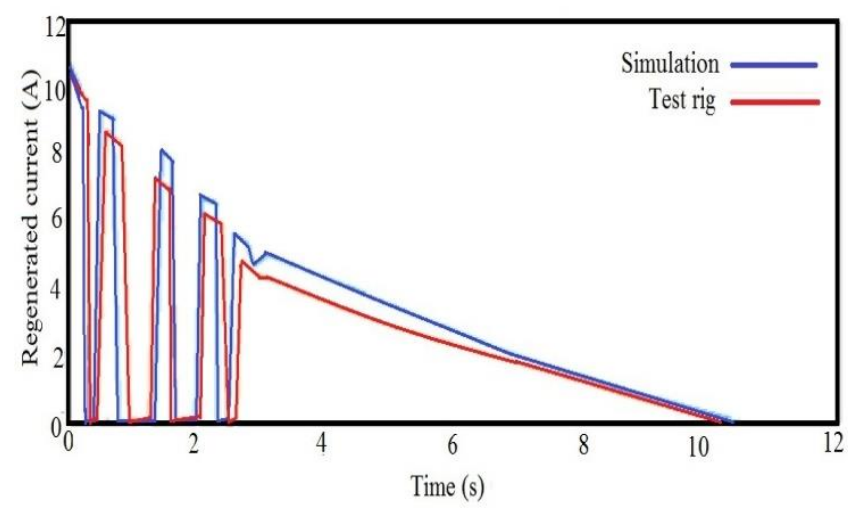

Fig. 30. Simulation and test rig Regenerated current in stopping state on the oily-surface (asphalt)

\section{CONCLUSION}

In this study, a new regenerative braking system is simulated and tested at very low speed rates lower than $10 \mathrm{~km} / \mathrm{h}$. Two modes of braking are applied in this system, one of them for reducing speed and the other one dealing with complete stopping. The proposed system allows speed reducing mode by using regenerative braking torque and for the emergency brake situation and complete stopping a constant mechanical torque brake with regenerative torque is allowed. The anti lock system is operated by controlling the load torque from the generator by changing the states (on-off) of the transistor, which allows current to pass and produce the electric field for the generator according to the error between the measured slip- ratio of the vehicle and the desired slip-ratio based on the surface condition. The state of the transistor is set to off if the measured slip-ratio is larger than the desired slip-ratio and set to on when the measured slip-ratio is smaller than the desired slip-ratio. One feature of the anti lock regenerative braking used in a golf cart is utilizing a large gear ratio reduction to allow the system to recover energy at low speed rates of the vehicle. By this system, the recovered energy reaches to $25 \%$ of energy losses in thermal energy. The RABS which is studied in this paper is easy to adapt and can be used for others hybrid vehicles.

\section{REFERENCES}

[1] Tehrani.M.M, Hairi, Yazdi.M.R, Haghpanah, Jahromi, Esfahanian.V, Amiri.M, Jafari, A, R, "Design of Anti lock Regenerative braking system for series Hyprid electric vehicle," in International journal of Automative Engineering, vol.1, number 2, June 2011, pp.14-27.

[2] L. A. S. B. Martins, J. M. O. Brito, A. M. D. Rocha, and J. J. G. Martins, "Regenerative Braking Potential and Energy Simulations for a Plug-In Hybrid Electric Vehicle Under Real Driving Conditions," pp. 525-532, 2009 .

[3] Wimj.c.Melis, "Fully Regenerative braking and improved acceleration for electrical vehicles," in International journal of sustainable energy development (IJSED), vol.2, issues 1 and 2, March/June 2013, pp. 7580.

[4] Wicks, F, Donnelly K,"Modeling Regenerative braking and storage for vehicles,"S.Hall, IEEE Energy conversion ENG. Conf., 1997, 20302035.

[5] Gao, Y, Chen L, and Ehsani M,"Investigation of the effectiveness of regenerative braking for EV and HEV," in society of Automotive engineers (SAE) J., sp-1466, paper No. 1999-01-2901-1999.

[6] Cikanek S. R., Bailey K. E., "Regenerative braking system for Hybrid electric vehicle," in Proc. Amer. Control Conf., Anchorage, AK, May 2002, 3129-3134.

[7] Yeo, H, Kim H,"Hardware in the loop simulation of regenerative braking for a hybrid electric vehicle,"in Proc. Inst. Mech. Eng. Vol. 216, 2002, pp.855-864

[8] Gao, H, Gao Y, Ehsani M,"Design issues of the switched reluctance motor drive for propulsion and regenerative braking in EV and HEV," IEEE Electronic Mach. Drives. Conf., (2001), 571-575.

[9] Sagar. M, Sudeendra. K, Kamalakanta. M, "Regenerative and Anti-Lock Braking System in Electric Vehicles", Proc. of IEEE International Conference on Advanced Communication, Control and Computing Technologies (ICACCCT), Tamilnadu, India, May 2014

[10] KEC,Ghaziabad,"Regenerative braking for an electric vehicle using hybrid energy storage system," in International journal of electrical and electronics engineering research(IJEEEK), vol.3, issue 4, Oct 2013, pp. $42-45$.

[11] Mike.B. Improving Alternator Efficiency Measurably Reduces Fuel Costs. [20th Apr 2017]; Available from:http:// www.delcoremy.com/AlternatorsHighEff.aspx.

[12] "Regen Braking" Q4D Sales Information Web Page, http://4qd.co.uk/fea/regen.html, viewed: [ 15th Jan 2017]; 
[13] Michael.K,"Through-life management of electric vehicles," $2^{\text {nd }}$ international through-life engineering services conference-Ashutosh Tiwari, Jul 2013

[14] Charette RN. This Car Runs on Code. 2009 [25th February 2013]; Available from: http://spectrum.ieee.org/green-tech/advanced-cars/thiscar- runs-on-code. 